\title{
A utilização do plano diretor de informática como prática de ensino do processo de automação em Biblioteca escolar
}

The use of the computer director's plan as a practice for teaching the school Library automation process

\section{El uso del plan maestro de TI como práctica docente para el proceso de automatización en una biblioteca escolar}

Cenidalva Miranda de Sousa TEIXEIRA ${ }^{1}$

Cecilna Miranda de Sousa TEIXEIRA ${ }^{2}$

\section{Correspondência}

Autor para correspondência: Cenidalva Miranda de Souza Teixeira Endereço completo: Av dos Holandeses, 1, Condomínio Palazzo Verona - Laguna, ap.101-Ponta do Farol 65077-635 São Luís - Ma

E-mail: cenidalva@gmail.com ORCID- 0000-0003-0642-1028

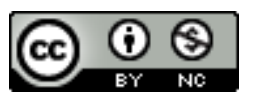

Submetido em: 01/12/2019

Aceito em: 02/01/2020

Publicado em: 22/05/2020

\footnotetext{
${ }^{1}$ Doutora em Engenharia Elétrica pela Universidade Federal do Maranhão (UFMA) e Professora Associada do Departamento de Biblioteconomia-UFMA.

2 Graduada em Gestão Empresarial. Aluna do Curso de Biblioteconomia na Universidade Federal do Maranhão-UFMA.
} 


\section{RESUMO}

Estudo sobre a prática de ensino do processo de automação em biblioteca escolar, com utilização do plano diretor de informática - PDI para automação dos serviços, que visa estruturar todo o processo em relação ao acervo e usuário existente no âmbito da biblioteca escolar da UEB Rosália Freire. Tem como objetivo geral destacar o PDI como prática de ensino para elaboração de uma proposta de automação para a biblioteca da referida unidade escolar, tornando-o um parâmetro à facilidade de uso na rotina de trabalho. Tem como objetivos específicos identificar as necessidades da biblioteca escolar da UEB Rosália Freire; elaborar um levantamento dos serviços e rotinas da referida biblioteca; estruturar um diagnóstico destinado à automação; utilizar o PDI como ferramenta no processo de automação. A metodologia deste estudo corresponde a uma pesquisa exploratória e descritiva, pautada na pesquisa bibliográfica, considerando vários autores e estudos explanados em sala de aula na disciplina de Automação de Unidades de Informação. Para elucidar os questionamentos e compreensão acerca da automação na biblioteca da UEB Rosália Freire, fez-se uso da observação do ambiente para análise inicial da ergonomia no espaço da biblioteca. Conclui-se que, como toda unidade de informação requer uma organização para que seus produtos e serviços sejam oferecidos com qualidade, a implantação dos serviços automatizados torna-se necessário para que haja controle e oferta desses serviços aos usuários no ambiente da escola. A utilização do PDI como ferramenta de estudo para automação de bibliotecas consistiu num aprendizado prático para os alunos, permitindo maior clareza nos processos de automação.

Palavras-chave: automação na Unidade de Informação. Biblioteca escolar. Ferramentas de ensino. Plano Diretor de Informática.

\section{ABSTRACT}

A study on the teaching practice of the automation process in a school library, using the computer master plan - PDI for automation of services, which aims to structure the entire process in relation to the collection and user existing within the scope of the UEB school library Rosália Freire. Its general objective is to highlight the PDI as a teaching practice for the elaboration of an automation proposal for the library of the referred school unit, making it a parameter to the ease of use in the work routine. Its specific objectives are to identify the needs of the UEB school library Rosália Freira; draw up a survey of library services and routines; structure a diagnosis for automation; use the PDI as a tool in the automation process. The methodology of this study corresponds to an exploratory and descriptive research, based on the bibliographic research, considering several authors and studies explained in the classroom in the discipline of Information Units Automation. In order to elucidate the questions and 
comprehension about automation in the library of the UEB Rosalia Freire, we made use of the observation of the environment for the initial analysis of the ergonomics in the space of the library. It is concluded that, as every information unit requires an organization to provide its products and services with quality, the implementation of automated services becomes necessary to control and offer these services to users in the school environment. The use of PDI as a study tool for library automation consisted of a practical learning for the students, allowing greater clarity in the automation processes.

Keywords: Automation in the Information Unit. School library. Teaching tools. Computer Master Plan.

\section{RESUMEN}

Estudio sobre la práctica docente del proceso de automatización en una biblioteca escolar, utilizando el plan maestro de TI - PDI para la automatización de servicios, que tiene como objetivo estructurar todo el proceso en relación con la colección y el usuario existentes dentro del alcance de la biblioteca escolar UEB Rosália Freire. Su objetivo general es destacar el PDI como práctica docente para la elaboración de una propuesta de automatización para la biblioteca de esa unidad escolar, convirtiéndola en un parámetro para facilitar su uso en la rutina laboral. Sus objetivos específicos son identificar las necesidades de la biblioteca escolar UEB Rosália Freire; preparar una encuesta de los servicios y rutinas de esa biblioteca; estructurar un diagnóstico para la automatización; use el PDI como herramienta en el proceso de automatización. La metodología de este estudio corresponde a una investigación exploratoria y descriptiva, basada en la investigación bibliográfica, considerando varios autores y estudios explicados en el aula en la disciplina de Automatización de Unidades de Información. Para aclarar las preguntas y la comprensión sobre la automatización en la biblioteca UEB Rosália Freire, se utilizó la observación del entorno para el análisis inicial de la ergonomía en el espacio de la biblioteca. Se concluye que, como cada unidad de información requiere una organización para que sus productos y servicios se ofrezcan con calidad, la implementación de servicios automatizados se hace necesaria para que haya control y oferta de estos servicios para los usuarios en el entorno escolar. El uso del PDI como herramienta de estudio para la automatización de bibliotecas consistió en un aprendizaje práctico para los estudiantes, lo que permitió una mayor claridad en los procesos de automatización.

Palabras clave: Automatización en la Unidad de Información. Biblioteca escolar. Herramientas de enseñanza. Plan maestro de informática. 


\section{INTRODUÇÃO}

A informatização está cada vez mais presente na vida cotidiana. É praticamente impossível ignorá-la em uma sociedade globalizada e imediatista. A dita revolução das tecnologias de comunicação e informação (CASTELLS, 1999) coloca o computador e demais tecnologias digitais como instrumentos básicos da comunicação, economia e gestão. Aproveitando-se das tecnologias à sua volta, o ser humano busca métodos para facilitar as atividades manuais e executá-las com maior rapidez e eficiência. A criação de softwares para as mais diversas áreas é um meio de tornar as atividades totalmente manuais em atividades parcialmente manuais.

Na perspectiva das unidades de informação, a automação passa a ser um recurso no gerenciamento informacional, reduzindo tempo, incrementando rapidez na recuperação e processamento da informação, facilitando as tarefas dos bibliotecários e o suprimento das necessidades informacionais dos usuários. Nesse contexto, é necessário que os bibliotecários estejam preparados para gerenciar tais recursos. Fazer a escolha correta do software a ser implantado na biblioteca, administrar sua implantação e acompanhar seu manuseio e treinamento aos usuários são ações que farão toda a diferença no produto final.

Escolher um software adequado para bibliotecas, considerando seu tipo, funções, público a que se destina, entre outros fatores, exige o máximo de cautela. Analisar alguns critérios que perpassam por suas funções e chegam até a avaliação desse software é parte intrínseca desse processo. No 
que tange à biblioteca escolar, sobre a qual este trabalho aborda, deve-se considerar também, para a implantação de um software, os objetivos de modo holístico e em particular da instituição na qual ela será inserida.

Para as bibliotecas, a automação é de suma importância, pois permite agilidade de seus serviços rotineiros e possibilita maior rapidez na recuperação da informação. Conforme Rodrigues e Prudêncio (2009, p. 9):

Nas bibliotecas e centros de informação, a automação surge para oferecer um atendimento eficaz e eficiente ao usuário, poupar tempo, otimizar os processos, atender a demanda, auxiliar a aquisição, tornar a organização mais precisa e principalmente atender às necessidades do usuário em curto espaço e tempo.

Nessa perspectiva, o Plano Diretor de Informática (PDI) surge como uma ferramenta que possibilita criar uma proposta de automação de forma sistêmica para a biblioteca da Unidade Escolar Básica Rosália Freire.

Este trabalho consiste em uma experiência prática dos estudos realizados na disciplina Automação em Unidade de Informação, que utiliza o PDI para elaborar a proposta de automação. Essa proposta inicia com o estudo do ambiente, observando as rotinas e serviços oferecidos para, então, iniciar o processo de escolha de softwares. Para esse processo, faz-se um estudo dos critérios de seleção e avaliação de softwares para bibliotecas a partir de três textos sobre a temática: Marascos e Mattes (1998); Côrte et al. (1999); e Café, Santos e Macedo (2001). Essa prática é relevante no contexto da referida disciplina, pois proporciona aos alunos uma vivência real sobre o 
trabalho do bibliotecário na organização de bibliotecas e de outros espaços com o uso de softwares, os quais favorecem um melhor gerenciamento das rotinas.

Dessa forma, tem-se como objetivo geral apresentar o processo de automação da biblioteca escolar com a utilização do plano diretor de informática - PDI, considerado uma ferramenta de ensino e aprendizagem para o planejamento desse processo. O estudo tem como cenário a biblioteca da Unidade Escolar Básica Rosália Freire, que precisa automatizar seu sistema por ainda ser totalmente manual.

\section{REFERENCIAL TEÓRICO}

O conceito de biblioteca escolar se amplia ao longo dos anos. Inicialmente, servia de guarda e conservação de material impresso ou eletrônico; em seguida passou da condição de formadora de leitores para atuar na formação de pesquisadores. Hoje, a biblioteca escolar é vista como um espaço mediador de informação. Côrte e Bandeira (2011, p. 6) resumem bem essas funções quando dizem que:

A biblioteca escolar serve de suporte aos programas educacionais, atuando como um centro dinâmico, participando, em todos os níveis e momentos, do processo de desenvolvimento curricular e funcionando como laboratório de aprendizagem integrado ao sistema educacional.

Nesse aspecto, percebe-se a importância da biblioteca escolar para a formação de bons leitores e de cidadãos críticos. Entende-se que a biblioteca escolar automatizada consegue comportar um maior volume informacional, ser mais eficiente e 
oferecer novos serviços para seu público. A modernização tecnológica alcança as bibliotecas. Usuários e máquinas agora interagem e o trabalho do bibliotecário passa a ser mais ágil.

Atualmente, uma grande parte das bibliotecas faz uso dos computadores nos seus serviços. Contudo,

Falar da automação de serviços e sistemas de informação de bibliotecas [...] é mais do que falar de uso direto de computadores, construção e acesso a bases nas bibliotecas [...] Não se trata de inundar as bibliotecas [...] com computadores e bases de dados, como que caídos de pára quedas. Não são poucos os estudos realizados mostrando como a simples informatização leva apenas a que as mesmas coisas sejam feitas com maior rapidez, além do acúmulo de equipamento sofisticado sendo utilizado como simples máquinas de escrever. O primeiro ponto é entender desde a base técnica do processo de automação até o verdadeiro uso da informação. [...] (CÔRTE et al., 2002, p. 19).

Essa compreensão deve ser realizada ainda no ambiente acadêmico. O curso de Biblioteconomia da Universidade Federal do Maranhão, por exemplo, possui três disciplinas do currículo que subsidiam o aluno na automação de bibliotecas, justamente para que o futuro profissional atenda às exigências do mercado, a saber: Elementos de informática, que é ministrada no segundo período; Tecnologia e gerenciamento da informação, no quarto período; e Automação de Unidades de Informação, no sétimo período. Nesta última é enfatizado o processo de automação de unidades de informação, quando os alunos criam um Plano Diretor de Informática - PDI. Esse conhecimento desmitifica a vinculação estrita do uso de computadores com automação.

Nessa perspectiva, Teixeira e Santos (2006, p. 3) afirmam que: 
[...] com o crescimento contínuo das áreas do conhecimento e o advento de novas tecnologias, torna-se inevitável a adoção da automação nos processos de uma biblioteca, objetivando a recuperação da informação bem como sua disseminação de forma rápida e precisa.

Agilizar e manter a qualidade dos serviços é, sem dúvida, um dos pontos relevantes na automação de bibliotecas. Percebese que os impactos causados pelos recursos tecnológicos nas bibliotecas são notoriamente facilitadores do processo de trabalho do bibliotecário. Mas, infelizmente, para modernizar uma biblioteca e democratizar a informação são evidentes o dispêndio de recursos financeiros.

Vale ressaltar que os softwares livres não devem ser confundidos com os softwares gratuitos, pois os softwares gratuitos assumem outra perspectiva.

O software gratuito ou freeware é uma categoria de programas para computador que permite sua distribuição, instalação e uso de forma gratuita sem que aja alteração em seu estado original ou uso comercial por terceiros. A gratuidade deste tipo de software não o isenta da figura de um proprietário, que muitas vezes lança softwares gratuitos como "amostra grátis" para seus programas comerciais (HÜBNER; GUILHERME, 2009, p. 4).

Portanto, os softwares gratuitos podem ser softwares comerciais, que apenas liberam uma demonstração gratuita. Já os softwares livres são passíveis de modificações, cópias e compartilhamentos sem nenhuma restrição, possibilitando que a unidade de informação o adeque segundo as suas necessidades.

Em contrapartida, não há um sistema ideal para as bibliotecas e sim um sistema adequado para a instituição. Por 
isso, o processo de implantação de softwares em bibliotecas é uma tarefa complexa, que exige planejamento e avaliação. Por esse motivo, a utilização do PDI contempla o interesse de uso como mecanismo de ensino e aprendizagem sobre a gestão de automação. O PDI permitiu estudar a biblioteca como um todo, planejar todo o processo de automação, bem como o processo de escolha de softwares.

Dentre os softwares livres, estes atualmente se apresentam como uma ferramenta já consolidada e exercem grande impacto nas organizações. Silva (2007) apresenta alguns aspectos que motivam o uso dos softwares livres, considerando as suas razões técnicas, que permitem uma maior flexibilidade e liberdade de adaptação, segurança/transparência/privacidade, melhor aderência aos padrões (interoperabilidade), qualidade (estabilidade, confiabilidade, disponibilidade); as razões econômico-financeiras, que correspondem à redução de custos de hardware e software, e maior autonomia por parte do fornecedor; e as razões ideológicas, referentes à filosofia e aos princípios de inclusão digital e social.

Segundo Hexsel (2002, p. 1),

A característica mais importante do software livre é a liberdade de uso, cópia, modificações e redistribuição. Esta liberdade é conferida pelos autores do programa e é efetivada através da distribuição do código fonte dos programas, o que os transforma em bens públicos, disponíveis para utilização por toda a comunidade e da maneira que seja mais conveniente a cada indivíduo.

Os softwares livres são apresentados como uma alternativa diante dos softwares proprietários, posto que são limitados pelas leis de direitos autorais e impedem sua distribuição ou 
modificação sem prévia autorização de seus desenvolvedores. Estes, em sua grande maioria, estimam a sua distribuição por lucros, diferente dos desenvolvedores de softwares livres. Sobre isso, Hexsel (2002, p. 5) afirma que:

Os benefícios econômicos são muito maiores e mais importantes que a simples economia com o licenciamento de software. A robustez e confiabilidade do software livre provocam reduções significativas em custos operacionais. A disponibilidade do código fonte permite que os sistemas sejam adaptados às condições e necessidades dos usuários.

O software livre, ao adotar essa filosofia, torna-se um bem público disponível a toda a sociedade. Além dos benefícios econômicos, esses programas apresentam diversos benefícios sociais, como a sua livre publicação, a liberdade de utilização das ferramentas e, principalmente, o conhecimento gerado e disseminado a partir da criação desses sistemas. Nessa perspectiva, Hexsel (2002, p. 5) aponta outros benefícios sociais advindos dos softwares livres:

Outro benefício social importante é a transparência na codificação das informações tratadas pelos programas. Os formatos empregados para armazenar e tratar as informações são abertos porque o código fonte dos programas pode ser livremente examinado, e não existe assim a possibilidade de que, por exemplo, dados usados no serviço público sejam mantidos em formatos de propriedade de uma entidade privada. O mesmo raciocínio se aplica aos protocolos de comunicação empregados para a transferência de informações entre computadores ou sistemas.

Um exemplo interessante nessa categoria de software livre é o Biblivre. Além do custo zero, é uma ferramenta de fácil acesso, ágil e prática; funciona perfeitamente com os sistemas operacionais Windows, Linux, Unix ou outro compatível; possui 
interfaces simples; sua busca pode ser realizada por autor, título, assunto, ISBN, entre outros; possibilita a impressão e leitura de obras que estão em domínio público, entre várias outras facilidades, além de contemplar um manual que está disponível em três idiomas.

\section{METODOLOGIA}

A metodologia utilizada foi a pesquisa exploratória e descritiva, a partir de um relato de experiência, pelo qual se buscou pontuar a implantação de um Plano Diretor de Informática. Os procedimentos foram pautados na pesquisa bibliográfica, considerando os autores que discutissem as seguintes temáticas: automação de bibliotecas e critérios para avaliação e escolha de softwares para bibliotecas. Os autores selecionados foram: Marasco e Mattes (1999), Corte et al. (2002), Café, Santos e Macedo (2001) sobre software livres; Silva (2007) e Teixeira et al. (2014) sobre o PDI; e Juliano (2007) e Teixeira e Marinho (2017, 2018).

A pesquisa de campo foi realizada com visitas à biblioteca, com o objetivo de conhecer e entender seu funcionamento para elaborar uma proposta de automação. A coleta de dados se deu com entrevista envolvendo o profissional bibliotecário, de modo a identificar os serviços e o alcance destes. Utilizou-se também os procedimentos de elaboração do PDI, que consiste nas seguintes etapas: levantamento das necessidades da unidade de informação; problemas atuais e descrição das áreas afetadas com os procedimentos atuais; análise das atividades, apresentando a 
solução e priorizando seu desenvolvimento; dimensionamento dos recursos necessários para desenvolver os projetos (custo de hardware, software, linhas de comunicação, treinamento, etc.); e cronograma previsto para execução e cumprimento de metas.

O locus da pesquisa foi a biblioteca da Unidade Escolar Rosália Freire, situada na Avenida dos Portugueses, s/n, no bairro Vila Embratel, cuja missão é garantir no processo pedagógico o acesso à informação, estimular a leitura e promover os serviços de apoio e aprendizado, visando formar um cidadão leitor com habilidades e competências para o uso eficaz da informação nesse ambiente. É vinculada à Secretaria Municipal de Educação (SEMED), com acervo voltado ao corpo pedagógico e discente da escola.

Os acervos dão suporte à leitura e às fontes de trabalhos didáticos para os alunos do Ensino Fundamental e Ensino Médio. As obras de referência são biografia, educação, português, matemática, ciências, geografia, artes, literatura brasileira, literatura maranhense e história.

O acervo é composto por 2.600 livros e não possui acervo multimídia. A modalidade de aquisição é por meio de doação pelo Ministério da Educação (MEC), através da SEMED, com livros paradidáticos e didáticos para os alunos. Em relação ao funcionamento da biblioteca, a mesma não possui uma rotina em seu horário, que é organizado pela necessidade do professor em utilizar em alguns momentos de leitura e pesquisa.

O sistema de empréstimo é totalmente manual e conta com o critério de confiança, sem controle dos livros ou utilização de 
fichas. O sistema de empréstimo não é uma prática rotineira. Em várias ocasiões, o próprio professor fica encarregado de ser o mediador para o recebimento e devolução do acervo à biblioteca.

\section{RESULTADOS E DISCUSSÃO}

$\mathrm{Na}$ construção do PDI fez-se um levantamento das necessidades do ambiente de estudo. Dessa forma, a estrutura utilizada contou com os seguintes passos: conhecer as metas da biblioteca; levantar suas necessidades; observar os problemas atuais, áreas afetadas com os procedimentos atuais; analisar o custo-benefício da solução apresentada (hardware, software e pessoal); planejar a escolha do software observando as prioridades dos projetos (planejamento dos sistemas); e acompanhar os resultados. Esses passos já foram adaptados de Silva (2007) e Teixeira e Marinho (2017, 2018).

Como resultado do trabalho prático, observou-se que o PDI contemplou as informações necessárias que viabilizaram a indicação do software livre para biblioteca. Os softwares livres e/ou proprietário são opções para escolha, mas deve ser feita mediante a necessidade e possibilidade da instituição, tanto no requisito de suporte à demanda quanto em torno da situação financeira atual.

Para a escolha de um software, selecionaram-se estudos sobre a metodologia e os critérios de avaliação de software para bibliotecas, que são: Marasco e Mattes (1998), Corte et al. (1999) e Café, Santos e Macedo (2001). Outro estudo corresponde à análise dos softwares disponíveis no mercado para 
automação de bibliotecas. Dentre os diversos softwares, dois deles, o Biblivre e o KOHA, foram escolhidos para uso prático no laboratório. Além de fácil instalação e operacionalidade, eles são softwares livres gratuitos.

A partir da discussão foi feita uma análise sobre o software e os custos operacionais para a escolha e adequação na instituição, conforme as necessidades e demandas da biblioteca. Nesse sentido, a situação relatada, vivenciada e observada através dos levantamentos na visita técnica e, seguindo a metodologia especificada, foi possível realizar o levantamento das necessidades da biblioteca seus problemas bem como a descrição das áreas afetadas com os procedimentos atuais, analisou-se as atividades, a fim de encontrar a solução adequada além de dimensionar os recursos necessários para desenvolver os projetos envolvendo os custos de hardware, software, linhas de comunicação, treinamento, etc. finalizando com 0 cronograma previsto para execução e cumprimento de metas.

Após o cumprimento da metodologia especificada optou-se pela escolha do software Biblivre, que atende às necessidades da biblioteca em estudo. Dentre os requisitos básicos para implantação dos recursos do Biblivre destacam-se: integração de todas as funções da biblioteca, possibilidade de customização (personalização) do sistema, acesso via browser (Internet), armazenamento de documentos digitais e disponibilização online do acervo.

O Biblivre disponibiliza as rotinas e subrotinas dos principais procedimentos realizados em bibliotecas, tais como: busca e 
recuperação da informação; circulação, mediante o controle do acesso para consulta; reserva, empréstimo e devolução de exemplares do acervo; catalogação de material bibliográfico, de multimídias e objetos digitais, inclusive com controle de autoridades e de vocabulário; transferência de registros entre bases de dados; controle do processo de aquisição de novos itens para o acervo.

A interface de administração do Biblivre ainda permite a gerência da tipologia de usuários, das permissões de acesso e do uso do sistema, das configurações do servidor Z39.50 e das características do programa. A manutenção do sistema prevê a reindexação das bases de dados e a geração de cópia de segurança.

Os requisitos para configuração do software Biblivre são: sistema operacional Windows, Linux, Unix ou compatível, sendo o Windows XP, Vista, Seven ou Superior. Ele pode ser instalado em qualquer sistema onde os seguintes programas funcionem adequadamente. Um dos requisitos para utilização do software é a instalação da versão 4.0 (MANUAL..., 2014).

\section{CONSIDERAÇÕES FINAIS}

A realidade da biblioteca da UEB Rosália Freire requer inovação para agregar maior interesse dos alunos em usufruir desse espaço como fonte de enriquecimento para o conhecimento, aliados à leitura como um grande potencial para o ensino e aprendizagem. Desse modo, é salutar a proposta de implantação de um sistema de automação da biblioteca mediante a realidade e necessidade como parâmetros. Tal proposta é 
benéfica para o fortalecimento do ensino e para o incentivo à leitura e pesquisa.

Para implantação de um sistema, as bibliotecas devem adquirir um software que otimize a gestão dos serviços e a organização dos materiais bibliográficos. A concepção do diagnóstico foi aferida através de visita técnica para identificação da estrutura e ergonomia existente no âmbito da mesma, e do modo como acontece o processo de trabalho, a fim de selecionar, através da análise, o melhor software para a instituição.

O PDI contempla o interesse de uso de ferramenta e mecanismo do processo de ensino e aprendizagem no planejamento e gestão de automação de unidade de informação. Ele permite estudar a biblioteca como um todo, planejar o processo de automação e a escolha de softwares.

A utilização do PDI permitiu aos alunos vivenciar na prática o processo de automação de uma unidade de informação, bem como devolver à sociedade o resultado deste estudo enquanto um produto, cumprindo, assim, o seu papel no ensino, pesquisa e extensão.

\section{REFERÊNCIAS}

CASTELLS, M. A sociedade em rede. São Paulo: Paz e Terra, 1999.

CAFÉ, L.; SANTOS, C.; MACEDO, F. Proposta de um método para escolha de software de automação de bibliotecas. Cí. Inf., Brasília, DF, v. 30, n. 2, p. 70-79, maio/ago. 2001.

CÔRTE, A. R.; BANDEIRA, S. P. Biblioteca escolar. Brasília, DF: Brinquet de Lemos, 2011. 
CÔRTE, A. R. et al. Automação de bibliotecas e centros de documentação: o processo de avaliação e seleção de softwares. Ciência da Informação, Brasília, v. 28, n. 3, set./dez. 1999.

CÔRTE, A. R. et al. Avaliação de softwares para bibliotecas e arquivos. 2. ed. rev. e ampl. São Paulo: Polis, 2002.

HEXSEL, R. A. Propostas de ações de Governo para incentivar o uso de software livre. Relatório Técnico do Departamento de Informática da UFPR, n. 004/2002, Curitiba, out. 2002.

HUBNER, E.; GUILHERME, R. C. Softwares livres para bibliotecas: uma ferramenta para a democratização do acesso à informação bibliográfica. In: CONGRESSO BRASILEIRO DE BIBLIOTECONOMIA E DOCUMENTAÇÃO, 22., 2009, Bonito, Mato Grosso do Sul. Anais[...] São Paulo: FEBAB, 2009. Disponível em: http://bibliodata.ibict.br/geral/docs/software livre para bibliot ecas.pdf Acesso em: 3 jul. 2017.

JULIANO. Plano Diretor de Informática, 2007. Disponível em: juliano.com.br/artigos.htm. Acesso em: 04 jun. 2014.

MARASCO, L. C.; MATTES, R.N. Avaliação e seleção de software para automação de centros de documentação e bibliotecas. Inf.Inf., Londrina, v.3, n.1, p.15-24, jan./jun.1998.

MANUAL Biblivre versão 4.1. Rio de Janeiro: Sociedade de Amigos da Biblioteca Nacional - SABIN, 2014.

RODRIGUES, A. M. M.; PRUDÊNCIO, R. B. C. Automação: a inserção da biblioteca na tecnologia da informação. Biblioline, João Pessoa, v. 5, n. 1/2, 2009.

SILVA, J. F. M. Software livre: modelos de seleção como subsídio à gestão bibliotecária. In: CONGRESSO BRASILEIRO DE BIBLIOTECONOMIA, DOCUMENTAÇÃO E CIÊNCIA DA INFORMAÇÃO, 22, 2007, Brasília. Anais[...] Brasília: FEBAB; ABDF, 2007. 1 CD-ROM.

TEIXEIRA, C. M. S.; SANTOS, J. C. O processo de escolha de software nas bibliotecas universitárias de São Luís-Ma. In: SEMINÁRIO NACIONAL DE BIBLIOTECAS UNIVERSITÁRIAS, 
2006, Salvador. Anais[...] Salvador: CBBU, 2006. Disponível em: http://www.snbu2006.ufba.br/resumos aprovados.pdf Acesso em: 19 set. 2009.

TEIXEIRA, C. M. S. et al. Software livre em bibliotecas públicas escolares na área Itaqui-Bacanga em São Luís - MA: estudos de casos. Rev. Inf. na Soc. Contemp., Natal, RN, v. 1, n. 1, jul./dez. 2014.

TEIXEIRA, C. M. S.; MARINHO, R. R. A prática de ensino e a gestão de automação de unidades de informação. RBBD (Online), v. 13, p. 110-131, 2017.

TEIXEIRA, C. M. S.; MARINHO, R. R. Planejamento e gestão do processo de automação de bibliotecas: experiências de aprendizado no curso de Biblioteconomia. ConCI: Conv. Ciênc. Inform., v. 1, p. 57-65, 2018. 